\title{
Oral health-related quality of life of patients with oral chronic graft-versus-host disease
}

\author{
Juliette Stolze ${ }^{1,2} \cdot$ Marlou Boor $^{1} \cdot$ Mette D. Hazenberg ${ }^{3} \cdot$ Henk S. Brand $^{2} \cdot$ Judith E. Raber-Durlacher $^{1,4}$. \\ Alexa M. G. A. Laheij ${ }^{1,5}$
}

Received: 26 November 2020 / Accepted: 1 April 2021 / Published online: 21 April 2021

(C) The Author(s) 2021

\begin{abstract}
Purpose Symptoms of oral chronic graft-versus-host-disease (cGVHD) may significantly affect the oral health-related quality of life (OHRQoL). This study aimed to assess the OHRQoL in patients with oral cGVHD and to examine whether oral cGVHD symptoms, mucosal cGVHD, and salivary gland function correlated with OHRQoL.

Methods Patients referred to the oral cGVHD outpatient clinic were included. Severity of oral mucosal cGVHD, oral cGVHD symptoms, and OHRQoL was assessed by the NIH OMS, NIH OSS, and OHIP-14, respectively. Unstimulated and stimulated whole salivary flow rates were determined and categorized into "hyposalivation," "normal salivary flow," and "hypersalivation." Results Of 56 included patients, $80 \%$ had mild, moderate, or severe oral mucosal cGVHD. Mean total score of OHRQoL was $16.5( \pm 11.7)$, negatively affected by functional problems. Patients reported highest scores regarding oral sensitivity and xerostomia. Significant correlations were found between severity of oral pain and OHRQoL and between oral sensitivity and OHRQoL. No correlation was found between oral mucosal cGVHD and OHRQoL. Patients with hyposalivation, normal salivary flow, and hypersalivation reported equal levels of OHRQoL.

Conclusion Results demonstrate that the OHRQoL was mostly negatively affected by complaints of oral pain and oral sensitivity and less by the severity of oral mucosal cGVHD assessed by the NIH OMS score. Special attention of (oral) health care professionals for patients with oral cGVHD is mandatory to alleviate their symptoms and improve OHRQoL.
\end{abstract}

Keywords Oral chronic-graft-versus-host disease $\cdot$ GVHD $\cdot$ OHRQoL $\cdot$ OHIP-14 $\cdot$ Quality of life $\cdot$ Hyposalivation $\cdot$ Xerostomia

Alexa M. G. A. Laheij

a.laheij@acta.nl

1 Department of Oral Medicine, Academic Centre for Dentistry (ACTA), University of Amsterdam and Vrije Universiteit Amsterdam, Gustav Mahlerlaan 3004, 1081, LA Amsterdam, The Netherlands

2 Department of Oral Biochemistry, Academic Centre for Dentistry (ACTA), University of Amsterdam and Vrije Universiteit Amsterdam, Amsterdam, The Netherlands

3 Department of Hematology Amsterdam UMC, University of Amsterdam, Amsterdam, The Netherlands

4 Department of Oral Maxillofacial Surgery, Amsterdam UMC, University of Amsterdam, Amsterdam, The Netherlands

5 Department of Preventive Dentistry, Academic Centre for Dentistry (ACTA), University of Amsterdam and Vrije Universiteit Amsterdam, Amsterdam, The Netherlands

\section{Introduction}

Hematopoietic stem cell transplantation (HSCT) is a widely used intervention to treat malignancies and other disorders of the hematopoietic system. The numbers of HSCTs performed continue to rise with more than 45,000 transplants reported in Europe in 2017, of which 18,281 were allogeneic HSCT (with donor-derived cells) [1]. With the introduction of less toxic reduced intensity and non-myeloablative preparative regimens for HSCT [2], HSCT also became a treatment option for older patients and patients with comorbidities.

While the survival rate of allogeneic HSCT is improving, the prevalence of graft-versus-host disease (GVHD) increases [3]. GVHD is a common and complex complication of allogeneic HSCT [4]. In patients with GVHD, a series of alloimmune reactions occur due to a mismatch in HLA antigens $[5,6]$ leading to acute or chronic GVHD. Nowadays, the distinction between acute and chronic GVHD (cGVHD) is made based on clinical manifestations, rather than based on 
time after HSCT with a classic dividing line at 100 days [7, 8]. Whereas acute GVHD typically presents specific clinical and histopathological features of the skin, liver, and/or gastrointestinal mucosa, chronic GVHD is defined as a systemic disease with multiorgan involvement, affecting the skin, mouth, genitals, eyes, liver, or lungs, presenting a wide range of signs and symptoms [5, 9-11]. Chronic GVHD is associated with increased morbidity and mortality. The 5-year non-relapse mortality rate of cGVHD ranges from 5 to $70 \%$ depending on factors such as prior acute GVHD, time between transplantation and development of cGVHD, donor type, and gender mismatch [12].

The incidence of cGVHD ranges between 30 and $70 \%$ depending on differences in age, type of donor, and postHSCT immunosuppressive therapy [5, 11, 13, 14]. Clinical features of cGVHD mimic multiple autoimmune or immunemediated conditions characterized by chronic inflammation [5]. The oral cavity is one of the most frequently affected anatomical sites [7]. Up to $80 \%$ of patients with cGVHD demonstrate oral involvement at a certain time point after HSCT $[15,16]$. Oral manifestations can be divided into mucosal disease, and/or salivary gland dysfunction and/or, less frequently, sclerotic changes [17]. Signs and symptoms include sensitivity of the oral mucosa to foods and liquids, oral pain, xerostomia and/or hyposalivation, increased risk for dental caries, difficulty speaking, recurrent fungal infections, recurrent superficial mucoceles, and mucosal presentations such as erythema, lichenoid or ulceration, taste alterations, dysphagia, and reduced mouth opening $[7,16]$. These complications may significantly affect the Oral Health-related Quality of Life (OHRQoL) of GVHD patients [18-20].

Due to the increased number of HSCT's performed and the increased survival rate after treatment, the quality of life $(\mathrm{QoL})$ of patients has become an important health outcome. However, to what extent oral cGVHD affects the OHRQoL of patients is still unclear $[10,17]$. Therefore, the aim of this study was to examine the OHRQoL of patients with oral cGVHD and to correlate it to oral mucosal cGVHD and salivary gland cGVHD.

\section{Patients and methods}

Recipients of allogeneic HSCT with oral cGVHD complaints referred to the department of Oral and Maxillofacial Surgery, Amsterdam UMC, location AMC, between September 2015 and December 2019 were included. Data concerning gender, age, time since HSCT, type of donor, and preparative conditioning regimen were retrieved from the medical records. During a clinical exam, the severity of oral mucosal cGVHD was assessed by a specialized dentist (JR-D), and patients were asked to fill out questionnaires about oral cGVHD symptoms and OHRQoL. Unstimulated and stimulated whole salivary flow rates were measured. The Ethics Review Committee of the Amsterdam UMC, location AMC, confirmed that the Medical Research Involving Human Subjects Act (WMO) does not apply to this study (W15_294 no. 15.0349). All patients provided written informed consent.

\section{Oral cGVHD assessment}

For assessment of the severity of oral mucosal cGVHD, the NIH cGVHD Oral Mucosal Score (NIH OMS) was used [19, 20]. The NIH OMS assesses the extent and severity of erythema, lichenoid lesions, ulcerations, and mucoceles in the oral cavity. The total score, ranging from 0 "no mucosal changes" to 15 "severe oral mucosal changes," is divided into four categories "no GVHD" (score 0), "mild" (scores 1-3), "moderate" (scores 4-9), and "severe" (scores 10-15).

For the assessment of patient-reported severity of oral cGVHD, patients were asked to complete the NIH Oral Symptom Scores (NIH OSS) [21, 22]. This questionnaire scores xerostomia, oral pain, and oral sensitivity during the last week, each rated on an 11-point scale ranging from 0 "not existing" to 10 "worst imaginable."

\section{Salivary flow rates}

To determine the presence and severity of salivary gland cGVHD, the unstimulated (UWS) and stimulated whole salivary flow rate (SWS) were measured. For the collection of unstimulated saliva, patients were asked to firstly swallow and thereafter salivate all accumulated saliva into a cup every $30 \mathrm{~s}$ during $5 \mathrm{~min}$. For the collection of stimulated saliva, participants were asked to follow the same procedure while chewing on flavorless paraffin gum. Salivary flow rates were determined gravimetrically and expressed as $\mathrm{mL} / \mathrm{min}$ [23]. The UWS and SWS were categorized into "hyposalivation" ( $<0.1 \mathrm{~mL} / \mathrm{min}$ resp. $<0.5 \mathrm{~mL} / \mathrm{min}$ ), "normal salivary flow" $(0.1-0.5 \mathrm{~mL} / \mathrm{min}$ resp. $0.5-2.0 \mathrm{~mL} / \mathrm{min})$, and "hypersalivation" (>0.5mL/min resp. $>2.0 \mathrm{~mL} / \mathrm{min}$ ) [24].

\section{OHRQoL assessment}

To assess the OHRQoL, patients were asked to complete the Dutch version of the Oral Health Impact Profile-14 (OHIP-14). The OHIP-14 comprises 14 items that measure seven domains of impact on patients OHRQoL: functional limitation, physical pain, psychological discomfort, physical disability, psychological disability, social disability, and social handicap $[25,26]$. For each item of the OHIP14, a 5-point Likert scale is used ranging from 0 "never" to 4 "very often" according to the frequency of the impact. The total OHIP-14 score ranges from 0 (excellent OHRQoL) to 56 (worst OHRQoL). 


\section{Statistical analysis}

All variables were summarized using descriptive statistics. IBM SPSS version 26 (IBM Inc., Armonk, USA) was used to perform data analyses. The Pearson's correlation coefficient $(r)$ was used to calculate correlations between oral mucosal cGVHD (NIH OMS total score) and oral cGVHD symptoms (NIH OSS scores), between oral cGVHD symptoms and OHRQoL (OHIP-14 total score) and between oral mucosal cGVHD and OHRQoL. The Kruskal-Wallis test was used to analyze differences in OHRQoL between patients with hyposalivation, normal salivary flow, and hypersalivation as determined by UWS and SWS. A $p$ value $<0.05$ was considered statistically significant.

In some cases, it was not possible to conduct some of the clinical assessments for practical reasons. These included time restriction because patients had multiple other examinations scheduled elsewhere in the hospital, patients had eaten just before the planned salivary flow assessment, or lack of a suitable room.

\section{Results}

\section{Patient characteristics}

Fifty-six patients were included. Table 1 shows the characteristics of these patients. There was an almost equal distribution in matched unrelated (MUD) and matched related donor (MRD) transplants. A majority of the patients received a non-myeloablative preparative regimen. For $75 \%$ of the patients, the assessments took place between 0 and 4.5 years after HSCT. There was one outlier of $>20$ years after HSCT.

\section{Oral cGVHD assessment}

The total oral mucosal cGVHD score ranged between 0 and 11 , with a mean score of $3.2( \pm 3.0)$. Most patients had mild
$(45.5 \%)$ or moderate $(30.9 \%)$ oral mucosal cGVHD. Twenty percent had no oral mucosal cGVHD. Only 2 patients (3.6\%) suffered from severe oral mucosal cGVHD. Most patients had lichenoid lesions, of which $25.5 \%$ were mild, $23.6 \%$ were moderate, and $18.2 \%$ severe (Fig. 1). About half of the patients had erythema, of which $32.7 \%$ were mild, $9.1 \%$ moderate, and $12.7 \%$ severe. Of all patients, $12.7 \%$ had ulcers involving $<20 \%$ of the mucosa, and $5.5 \%$ had ulcers involving $>20 \%$ of the mucosa. Mucoceles were reported by a quarter of the patients $(24.6 \%)$.

Subjective scores for oral cGVHD were available from 44 patients (78.6\%) (Fig. 2). Patients reported more severe oral sensitivity (mean $5.2 \pm 3.0$ ) and xerostomia (mean $5.1 \pm 3.3$ ) than oral pain (mean $3.4 \pm 3.2$ ).

\section{Salivary flow rates}

The whole salivary flow rates were assessed for 49 patients $(87.5 \%)$. The UWS ranged from 0 to $1.6 \mathrm{~mL} / \mathrm{min}$, and the SWS ranged from 0 to $5.6 \mathrm{~mL} / \mathrm{min}$. Based on UWS and SWS, $12 \%$ and $21 \%$ of the patients were categorized as hyposalivation (Fig. 3).

\section{Oral health-related quality of life}

The total OHIP-14 scores ranged from 0 to $42(n=56)$, with a mean score of $16.5( \pm 11.7)$. Figure 4 shows the distribution of scores on each of the OHIP-14 items. Items "have you had painful aching in your mouth" and "Have you found it uncomfortable to eat any foods because of problems with your teeth, mouth or dentures" and "Has your diet been unsatisfactory because of problems with your teeth, mouth or dentures?" and "Have you felt that your sense of taste has worsened because of problems with your teeth, mouth or dentures?" received higher scores. Items "Have you been totally unable to function because of problems with your teeth, mouth or dentures?" and "Have you been a bit irritable with other
Table 1 Characteristics of patients with oral chronic graftversus-host disease (cGVHD) at the time of enrollment

\begin{tabular}{lll}
\hline Patient characteristics & $n(\%)$ & Mean \pm SD (range) \\
\hline Age (years) & & $55.4 \pm 13.6(21-72)$ \\
$\begin{array}{l}\text { Time between HSCT treatment } \\
\text { and assessment (months) }\end{array}$ & $44.8 \pm 54.4(2-294)$ \\
Male & $31(55.4 \%)$ & \\
Female & $25(44.6 \%)$ & \\
MUD & $30(53.6 \%)$ & \\
MRD & $26(46.4 \%)$ & \\
Myeloablative conditioning & $10(17.9 \%)$ & \\
Reduced-intensity/non-myeloablative conditioning & $46(82.1 \%)$ & \\
\hline
\end{tabular}

HSCT hematopoietic stem cell transplantation, $M U D$ matched-unrelated donor, $M R D$ matched-related donor 

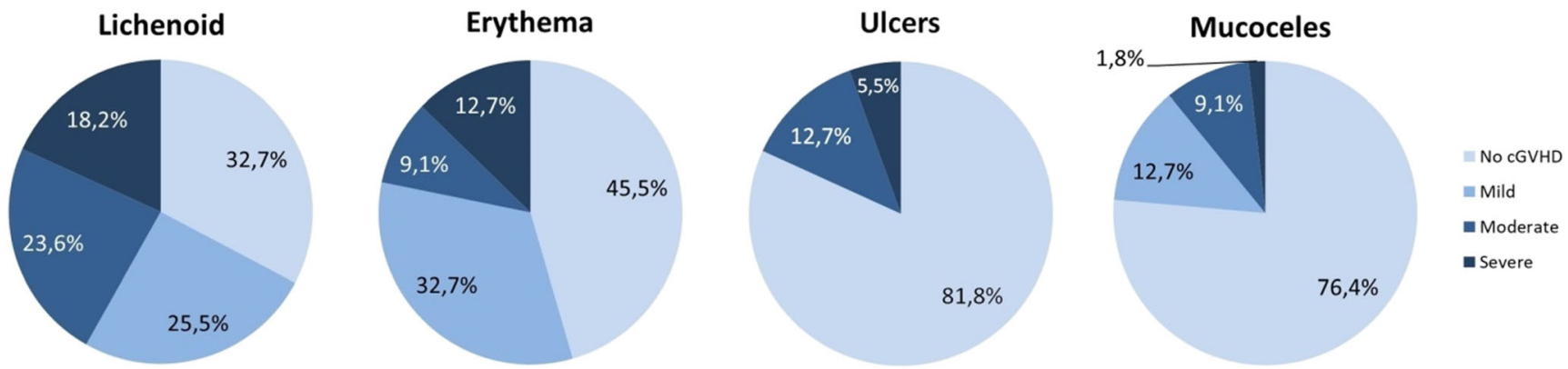

Fig. 1 Frequency and severity of lichenoid lesions, erythema, ulcers, and mucoceles in patients with oral chronic graft-versus-host disease (cGVHD) as assessed by NIH OMS $(n=55)$

people because of problems with your teeth, mouth or dentures?" gave the least problems for the patients.

\section{Oral mucosal cGVHD, oral cGVHD symptoms, and OHRQOL}

Significant moderate correlations were found between patientreported severity of oral pain and the OHRQoL $(r=0.519$, $p<0.0005$ ) and between patient-reported severity of oral sensitivity and the OHRQoL $(r=0.616, p<0.0005)$. Patients that reported more severe pain and sensitivity of the oral mucosa had a worse OHRQoL. No correlations were found between the severity of oral mucosal cGVHD and the OHRQoL $(r=0.248, p=0.068)$ and between patient-reported severity of xerostomia and the OHRQoL $(r=0.026, p=0.868)$.

Significant weak correlations were found between the severity of oral mucosal cGVHD and patient-reported severeness of xerostomia $(r=-0.312, p=0.039)$, oral pain $(r=0.313$, $p=0.038)$, and oral sensitivity $(r=0.477, p=0.001)$. Patients that had more severe oral mucosal cGVHD may report less

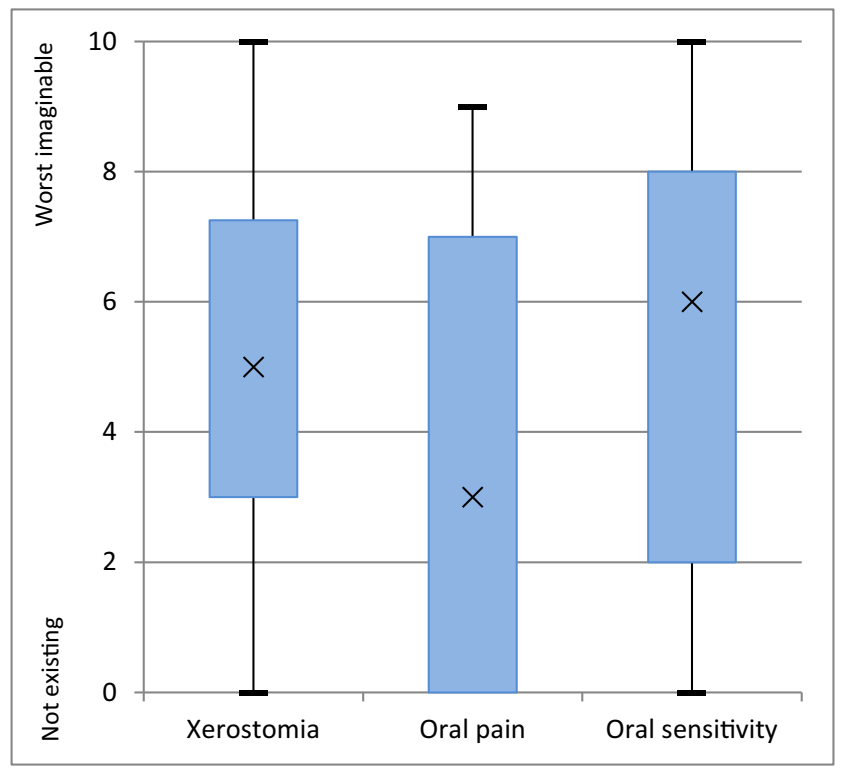

Fig. 2 Patient-reported severeness of oral chronic graft-versus-host disease (cGVHD) symptoms as assessed by NIH OSS. Distribution of scores $(n=44)$ severe xerostomia and more severe pain and sensitivity of the oral mucosa.

\section{Salivary flow rates and OHRQoL}

No differences in OHRQoL were found between patients with hyposalivation, normal salivary flow, and hypersalivation as measured by UWS $(p=0.700)$ and SWS $(p=0.104)$.

\section{Discussion}

This study is one of the first studies that assessed OHRQoL of patients with oral cGVHD using the OHIP-14 questionnaire. Our results demonstrate that the OHRQoL was mostly negatively affected by complaints of oral pain and oral sensitivity and less by the severity of oral mucosal cGVHD. The OHRQoL was affected in particular by functional problems with oral mucosal tissue, the dentition or dentures, like oral pain, uncomfortable eating, or altered taste. Social aspects had less impact on the OHRQoL. A similar pattern was found in a recent systematic review of the OHRQoL in patients with hematological cancers [27]. Functional complications impaired OHRQoL more severely than social aspects.

The OHIP-14 is an internationally validated and widely used questionnaire to assess the OHRQoL. The questionnaire is user friendly and is available in different languages. As a result, comparison is possible with other studies in the literature. To the best of our knowledge, there is no validated questionnaire available specifically designed for evaluating the OHRQoL of patients with oral cGVHD. In our experience, most problems faced by these patients are covered by items from the OHIP-14. The OHIP questions provide a global overview of a person's perception of the social impact of their oral disorder(s) on their well-being, while at the same time different aspects of impact are addressed. However, designing a specific validated questionnaire for evaluating OHRQoL in patients with oral cGVHD could be considered.

The mean OHIP-14 total score of 16.5 in the present study is relatively high compared to OHIP-14 scores of other hemato-oncologic patients, previously reported, implicating 
Fig. 3 Distribution of the salivary flow rate of oral chronic graftversus-host disease (cGVHD) patients $(n=49)$

\section{Stimulated salivary flow}

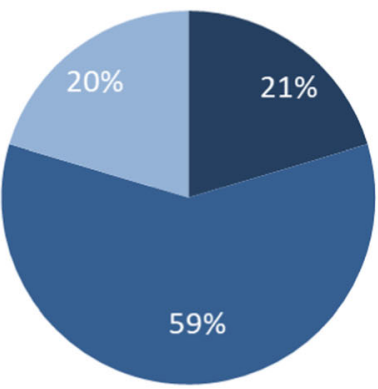

Unstimulated salivary flow

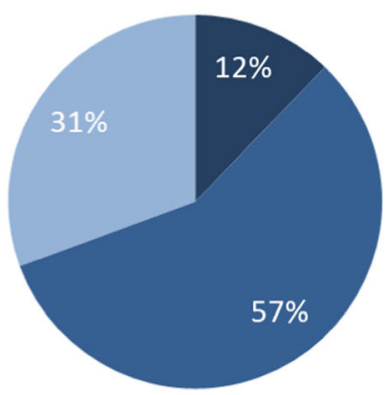

- hyposalivation

normal salivary flow

nypersalivation a worse OHRQoL in patients suffering from cGVHD. Mean OHIP-14 total scores of 4.48 [28] and 4.62 [29] have been described for patients with onco-hematologic diseases at admission of or scheduled for HSCT. A mean OHIP-14 score of 10.6 was reported for patients undergoing intravenous chemotherapy [30]. The lower OHIP-14 scores in the previous studies could be explained by the fact that these patients did not suffer from cGVHD or may have received adequate medications (e.g., opioids) to relieve oral pain caused by oral mucositis [31]. These strong analgesics are usually not prescribed to patients with oral cGVHD. On the other hand, it is difficult to interpret or compare the average OHIP total score as no scale has been drawn up in terms of low, moderate, or high OHRQoL. High scores on just two individual domains or items of the OHIP-14 can already indicate a significant effect on the QoL. Therefore, the total score does not do justice to problems that patients may experience in a specific part.
Usually, studies used questionnaires other than the OHIP-14 to assess the (OHR)QoL of cGVHD patients. Several studies reported a reduced QoL of cGVHD patients $[10,32,33]$, and correlations between QoL and symptoms of pain and fatigue [18] or xerostomia [16] have been reported as well. In one study among HSCT recipients, patients with extensive cGVHD had on average worse QoL, compared to patients with limited or without cGVHD [34]. In another study among HSCT recipients, of which $33.3 \%$ suffered from cGVHD, a reduced QoL was found [35]. Another study reported that the QoL correlated with oral mucositis due to HSCT [36]. However, information about presence or absence of GVHD was not reported in that study. In another study among HSCT recipients of which $69.3 \%$ suffered from cGVHD and $35.1 \%$ had oral cGVHD, no association between reduced QoL scores and dental disease and symptoms was observed [37].
Fig. 4 Distribution of the scores on the 14 items of the OHIP-14 of oral chronic graft-versus-host disease (cGVHD) patients $(n=$ 56)
1. trouble pronouncing words 2. sense of taste worsened 3. painful aching 4. uncomfortable eating

5. have been self conscious 6. felt tense 7. unsatisfactory diet 8. interrupting meals 9. difficult relaxing

10. have been embarrassed

11. have been irritable with other people 12. difficulty doing usual jobs 13. life in general less satisfying 14. totally unable to function

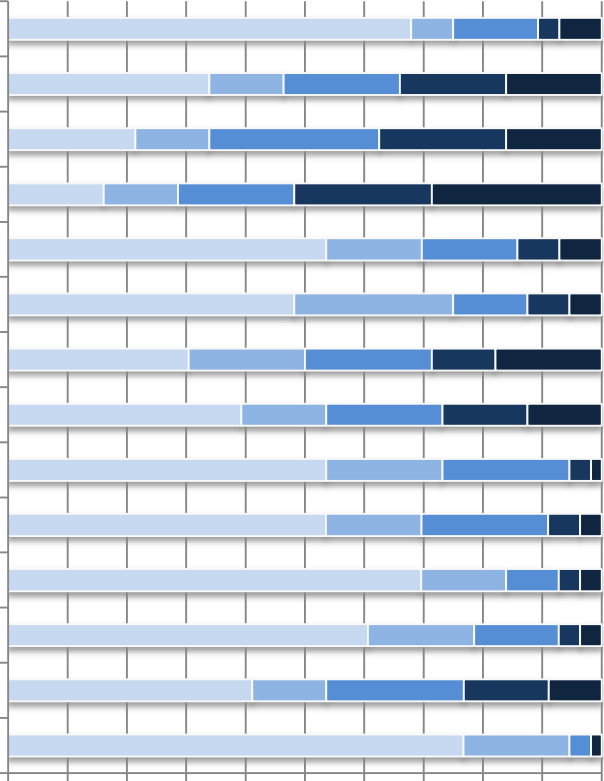

$\begin{array}{lllllllllll}0 \% & 10 \% & 20 \% & 30 \% & 40 \% & 50 \% & 60 \% & 70 \% & 80 \% & 90 \% & 100 \%\end{array}$ 0 'never' 1 'hardly ever'
ـ 3 'fairly often'
4 'very often' 
The OHRQoL was not highly affected for some situations, such as difficulty relaxing or the inability to perform usual jobs. A possible explanation could be the so-called response shift [9]. By having survived cancer and/or because of adaptation and acceptance to a chronic condition, like cGVHD, patients may adapt to their limitations and ultimately perceive better QoL than experienced before [37]. And, in patients with a severe systemic disease, oral health may become less of a priority, and oral symptoms may have less of an impact on the total health-related quality of life (HRQoL) and daily life.

According to Fall-Dickson et al. [17], no reliable clinical signs or related symptoms are known to predict the clinical course of oral involvement of cGVHD. Therefore, they recommended evaluating the impact of oral cGVHD on patients experience/symptoms and (oral health related) QoL. In the present study, oral mucosal cGVHD, assessed by a clinician using the NIH OMS, was significantly correlated with the severity of oral pain and oral sensitivity. However, this correlation was too weak to suggest that oral pain and oral sensitivity may predict the severity of oral mucosal cGVHD. A stronger correlation was found between oral pain and oral sensitivity and the OHRQoL. When determining or predicting the OHRQoL, focus should lie on patient-reported outcomes or symptoms. Since no correlation was found between severity of oral mucosal cGVHD and OHRQoL, clinical manifestations, such as lichenoid and erythema of the oral mucosa, do not necessarily imply worse OHRQoL. A similar result was found in the study of Imanguli et al. [38].

Different studies emphasize the prevalence or severity of xerostomia in HSCT recipients with oral cGVHD. Percentages of patients with xerostomia vary between $43 \%$ [16] and 77\% [38]. In HSCT patients compared to healthy controls, Brand et al. [39] found a significantly greater severity of xerostomia as well as several other oral complaints. Eighty-six percent of the patients reported having active GVHD or a history of GVHD. However, between patients with or without GVHD, no difference in severity of xerostomia was found. In the present study, patients reported more severe xerostomia than oral pain. A similar result was found by Fall-Dickson and co-workers [16], where xerostomia was more prevalent and severe than oral pain among oral cGVHD patients. The severity of xerostomia was associated with impaired HRQoL, which was also confirmed in another study $[16,38]$. Interestingly, in the present study, no correlation was found between the severity of xerostomia and OHRQoL. In addition, the weak negative correlation that was found between the severity of xerostomia and oral mucosal cGVHD may suggest that patients experienced less xerostomia when having more severe oral mucosal cGVHD. However, the clinical relevance may be questioned given the weakness of the correlation. Furthermore, patients with hyposalivation, normal salivary flow, and hypersalivation did not differ in OHRQoL. In contrast, in the study of
Imanguli et al. [39], among patients with cGVHD, a significant association was found between salivary gland dysfunction and lower OHRQoL. The low incidence of hyposalivation in the present study (only $12 \%$ and $21 \%$ based on UWS and SWS, respectively) could explain why no differences could be identified. Findings in the present study confirm the assumption that oral mucosal cGVHD and salivary cGVHD are two distinct manifestations of the disease $[15,40]$.

Due to the cross-sectional design of the study, all assessments were taken at a single time point, with varying time since HSCT and varying duration of cGVHD. Although all patients were suffering from oral cGVHD, its manifestations are known to be fluctuating in severity over time [4]. Therefore, future studies investigating the impact of oral cGVHD on (OHR)QoL should preferably have a prospective design and follow patients over a longer period of time and should include larger numbers of patients taking potential confounders into account.

To conclude, the results from the present study highlight the important observation that HSCT recipients who suffer from oral cGVHD have a lower OHRQoL. Special, long-term, attention aiming to reduce oral mucosal pain and sensitivity could relieve symptoms and may improve OHRQoL [41, 42].

Acknowledgements The authors like to acknowledge R.I.C. Slief, G. Momayez, and $\mathrm{H}$. Bouzia for their help with gathering the data. We thank all patients for participating in this study.

Author contribution J. Stolze contributed to conception, design, data acquisition and interpretation; performed all statistical analyses; and drafted and critically revised the manuscript. M. Boor contributed to conception and data acquisition and critically revised the manuscript. MD Hazenberg contributed to conception and design and critically revised the manuscript. HS Brand contributed to conception and data interpretation and critically revised the manuscript. JE Raber-Durlacher contributed to conception, design, and data acquisition and critically revised the manuscript. AMGA Laheij contributed to conception and design, contributed to analysis and data interpretation, and drafted and critically revised the manuscript.

Availability of data and material The data that support the findings of this study are available on request from the corresponding author.

Code availability Does not apply.

\section{Declarations}

Ethical approval Does not apply.

Consent to participate Does apply.

Consent for publication All authors gave their final approval and agree to be accountable for all aspects of the work.

Competing interests The authors declare no competing interests. 
Open Access This article is licensed under a Creative Commons Attribution 4.0 International License, which permits use, sharing, adaptation, distribution and reproduction in any medium or format, as long as you give appropriate credit to the original author(s) and the source, provide a link to the Creative Commons licence, and indicate if changes were made. The images or other third party material in this article are included in the article's Creative Commons licence, unless indicated otherwise in a credit line to the material. If material is not included in the article's Creative Commons licence and your intended use is not permitted by statutory regulation or exceeds the permitted use, you will need to obtain permission directly from the copyright holder. To view a copy of this licence, visit http://creativecommons.org/licenses/by/4.0/.

\section{References}

1. Passweg JR, Baldomero H, Basak GW, Chabannon C, Corbacioglu S, Duarte R et al (2019) The EBMT activity survey report 2017: a focus on allogeneic HSCT for nonmalignant indications and on the use of non-HSCT cell therapies. Bone Marrow Transplant 54(10): $1575-1585$

2. Shapira MY, Tsirigotis $P$, Resnick IB, Or R, Abdul-Hai A, Slavin S (2007) Allogeneic hematopoietic stem cell transplantation in the elderly. Crit Rev Oncol Hematol 64(1):49-63

3. Elad S, Raber-Durlacher JE, Brennan MT, Saunders DP, Mank AP, Zadik Y, Quinn B, Epstein JB, Blijlevens NMA, Waltimo T, Passweg JR, Correa MEP, Dahllöf G, Garming-Legert KUE, Logan RM, Potting CMJ, Shapira MY, Soga Y, Stringer J, Stokman MA, Vokurka S, Wallhult E, Yarom N, Jensen SB (2015) Basic oral care for hematology-oncology patients and hematopoietic stem cell transplantation recipients: a position paper from the joint task force of the Multinational Association of Supportive Care in Cancer/International Society of Oral Oncology (MASCC). Support Care Cancer 23(1):223-236

4. Mays JW, Fassil H, Edwards DA, Pavletic SZ, Bassim CW (2013) Oral chronic graft-versus-host disease: current pathogenesis, therapy, and research. Oral Dis 19(4):327-346

5. Mawardi H, Hashmi SK, Elad S, Aljurf M, Treister N (2019) Chronic graft-versus-host disease: Current management paradigm and future perspectives. Oral Dis 25(4):931-948

6. Dickinson AM, Norden J, Li S, Hromadnikova I, Schmid C, Schmetzer H, Jochem-Kolb H (2017) Graft-versus-leukemia effect following hematopoietic stem cell transplantation for leukemia. Front Immunol 8:496

7. Flowers MED, Parker PM, Johnston LJ, Matos AVB, Storer B, Bensinger WI, Storb R, Appelbaum FR, Forman SJ, Blume KG, Martin PJ (2002) Comparison of chronic graft-versus-host disease after transplantation of peripheral blood stem cells versus bone marrow in allogeneic recipients: long-term follow-up of a randomized trial. Blood 100(2):415-419

8. Lee SJ (2017) Classification systems for chronic graft-versus-host disease. Blood 129(1):30-37

9. Baker KS, Fraser CJ (2008) Quality of life and recovery after graftversus-host disease. Best Pract Res Clin Haematol 21(2):333-341

10. Depalo J, Chai X, Lee SJ, Cutler CS, Treister N (2015) Assessing the relationship between oral chronic graft-versus-host disease and global measures of quality of life. Oral Oncol 51(10):944-949

11. Fraser CJ, Bhatia S, Ness K, Carter A, Francisco L, Arora M, Parker P, Forman S, Weisdorf D, Gurney JG, Baker KS (2006) Impact of chronic graft-versus-host disease on the health status of hematopoietic cell transplantation survivors: a report from the Bone Marrow Transplant Survivor Study. Blood 108(8):2867-2873
12. Arora M, Klein JP, Weisdorf DJ (2011) Chronic GVHD risk score: a Center for International Blood and Marrow Transplant Research analysis. Blood. 118(26):6992

13. Blazar BR, Murphy WJ, Abedi M (2012) Advances in graft-versushost disease biology and therapy. Nat Rev Immunol 12(6):443-458

14. Shulman HM, Cardona DM, Greenson JK, Hingorani S, Horn T, Huber E et al (2015) NIH Consensus Development Project on Criteria for Clinical Trials in Chronic Graft-versus-Host Disease: II. The 2014 Pathology Working Group Report. Biol Blood Marrow Transplant 21(4):589-603

15. Bassim CW, Fassil H, Mays JW, Edwards D, Baird K, Steinberg SM, Cowen EW, Naik H, Datiles M, Stratton P, Gress RE, Pavletic SZ (2015) Oral disease profiles in chronic graft versus host disease. J Dent Res 94(4):547-554

16. Fall-Dickson JM, Mitchell SA, Marden S, Ramsay ES, Guadagnini JP, Wu T, St John L, Pavletic SZ, National Institutes of Health Chronic Graft-versus-Host Disease Study Group (2010) Oral symptom intensity, health-related quality of life, and correlative salivary cytokines in adult survivors of hematopoietic stem cell transplantation with oral chronic graft-versus-host disease. Biol Blood Marrow Transplant 16(7):948-956

17. Fall-Dickson JM, Pavletic SZ, Mays JW, Schubert MM (2019) Oral complications of chronic graft-versus-host disease. J Natl Cancer Inst Monogr 2019(53):54-62

18. Kelly DL, Lyon DE, Ameringer SA, Elswick RK (2015) Symptoms, cytokines, and quality of life in patients diagnosed with chronic graft-versus-host disease following allogeneic hematopoietic stem cell transplantation. Oncol Nurs Forum 42(3):265-275

19. Jagasia MH, Greinix HT, Arora M, Williams KM, Wolff D, Cowen EW et al (2015) National Institutes of Health Consensus Development Project on Criteria for Clinical Trials in Chronic Graft-versus-Host Disease: I. The 2014 Diagnosis and Staging Working Group Report. Biol Blood Marrow Transplant 21(3): 389-401.e1

20. Bassim CW, Fassil H, Mays JW, Edwards D, Baird K, Steinberg SM, Williams KM, Cowen EW, Mitchell SA, Cole K, Taylor T, Avila D, Zhang D, Pulanic D, Grkovic L, Fowler D, Gress RE, Pavletic SZ (2014) Validation of the National Institutes of Health chronic GVHD Oral Mucosal Score using component-specific measures. Bone Marrow Transplant 49(1):116-121

21. Navazesh M, Kumar SKS (2008) Measuring salivary flow. J Am Dent Assoc 139(May):35S-40S

22. Working Group 10 of the Commission on Oral Health, Research and Epidemiology (CORE) (1992) Saliva: its role in health and disease. Int Dent J Aug 42(4 Suppl 2):287-304

23. Slade GD, Spencer AJ (1994) Development and evaluation of the Oral Health Impact Profile. Community Dent Health 11(1):3-11

24. Van Der Meulen MJ, John MT, Naeije M, Lobbezoo F (2008) The Dutch version of the Oral Health Impact Profile (OHIP-NL): translation, reliability and construct validity. BMC Oral Health 8(1):1-7

25. Stolze J, Vlaanderen KCE, Raber-Durlacher JE, Brand HS (2020) The impact of hematological malignancies and their treatment on oral health-related quality of life as assessed by the OHIP-14: a systematic review. Odontology 108(3):511-520

26. Silva LC, Sacono NT, Freire MDCM, Costa LR, Batista AC, Silva GBL (2015) The impact of low-level laser therapy on oral mucositis and quality of life in patients undergoing hematopoietic stem cell transplantation using the oral health impact profile and the functional assessment of cancer therapy-bone marrow transplantation que. Photomed Laser Surg 33(7):357-363

27. Tinoco-Araujo JE, Orti-Raduan ESL, Santos D, Colturato VAR, Souza MP, Mauad MA, Saggioro TCM, Bastos RS, da Silva Santos PS (2015) Oral health-related quality of life before hematopoietic stem cell transplantation. Clin Oral Investig 19(9):23452349 
28. Grando LJ, Mello ALSF, Salvato L, Brancher AP, Del Moral JAG (2015) Impact of leukemia and lymphoma chemotherapy on oral cavity and quality of life. Spec Care Dent 35(5):236-242

29. Bellm LA, Epstein JB, Rose-Ped A, Martin P, Fuchs HJ (2000) Patient reports of complications of bone marrow transplantation. Support Care Cancer 8(1):33-39

30. Lee SJ, Kim HT, Ho VT, Cutler C, Alyea EP, Soiffer RJ, Antin JH (2006) Quality of life associated with acute and chronic graftversus-host disease. Bone Marrow Transplant 38(4):305-310

31. Chiodi S, Spinelli S, Ravera G, Petti AR, Van Lint MT, Lamparelli $\mathrm{T}$ et al (2000) Quality of life in 244 recipients of allogeneic bone marrow transplantation. Br J Haematol 110(3):614-619

32. Heinonen H, Volin L, Uutela A, Zevon M, Barrick C, Ruutu T (2001) Quality of life and factors related to perceived satisfaction with quality of life after allogeneic bone marrow transplantation. Ann Hematol 80(3):137-143

33. Kiss TL, Abdolell M, Jamal N, Minden MD, Lipton JH, Messner HA (2002) Long-term medical outcomes and quality-of-life assessment of patients with chronic myeloid leukemia followed at least 10 years after allogeneic bone marrow transplantation. J Clin Oncol 20(9):2334-2343

34. Pereira NF, da Silva PVR, Fukuoka CY, Michel-Crosato E, Gonçalves AS, Alves FA et al (2018) Measurement of oral health quality of life among patients who underwent haematopoietic stemcell transplantation. Braz Oral Res 32:e78

35. Dyer G, Brice L, Schifter M, Gilroy N, Kabir M, Hertzberg M, Greenwood M, Larsen SR, Moore J, Gottlieb D, Huang G, Hogg M, Brown L, Tan J, Ward C, Kerridge I (2018) Oral health and dental morbidity in long-term allogeneic blood and marrow transplant survivors in Australia. Aust Dent J 63(3):312-319

36. Imanguli MM, Atkinson JC, Mitchell SA, Avila DN, Bishop RJ, Cowen EW, Datiles MB, Hakim FT, Kleiner DE, Krumlauf MC, Pavletic SZ (2010) Salivary gland involvement in chronic graftversus-host disease: prevalence, clinical significance, and recommendations for evaluation. Biol Blood Marrow Transplant 16(10): $1362-1369$
37. Brand HS, Bots CP, Raber-Durlacher JE (2009) Xerostomia and chronic oral complications among patients treated with haematopoietic stem cell transplantation. Br Dent J 207(9):E17E17

38. Samim F, te Böhmer KL, Koppelmans RGA, Raber-Durlacher JE, Epstein JB (2019) Oral care for hematopoietic stem cell transplantation patients: a narrative review. Oral Health Prev Dent 17(5): 413-423

39. Haverman TM, Raber-Durlacher JE, Raghoebar II, Rademacher WMH, Rozema FR, Hazenberg MD et al (2020) Oral chronic graft-versus-host disease: what the general dental practitioner needs to know. J Am Dent Assoc 151(11):846-856

40. Noce CW, Gomes A, Copello A, Barbosa RD, Sant'anna S, Moreira MCR et al (2011) Oral involvement of chronic graftversus-host disease in hematopoietic stem cell transplant recipients. Gen Dent 59(6):454-458

41. Treister N, Duncan C, Cutler C, Lehmann L (2012) How we treat oral chronic graft-versus-host disease. Blood 120(17):3407-3418

42. Pavletic SZ, Martin P, Lee SJ, Mitchell S, Jacobsohn D, Cowen EW, Turner ML, Akpek G, Gilman A, McDonald G, Schubert M, Berger A, Bross P, Chien JW, Couriel D, Dunn JP, Fall-Dickson J, Farrell A, Flowers ME, Greinix H, Hirschfeld S, Gerber L, Kim S, Knobler R, Lachenbruch PA, Miller FW, Mittleman B, Papadopoulos E, Parsons SK, Przepiorka D, Robinson M, Ward M, Reeve B, Rider LG, Shulman H, Schultz KR, Weisdorf D, Vogelsang GB, Response Criteria Working Group (2006) Measuring therapeutic response in chronic graft-versus-host disease: National Institutes of Health consensus development project on criteria for clinical trials in chronic graft-versus-host disease: IV. Response criteria working group report. Biol Blood Marrow Transplant 12(3):252-266

Publisher's note Springer Nature remains neutral with regard to jurisdictional claims in published maps and institutional affiliations. 